\title{
DO “VIVER" E DO “MORRER” NOS ESTUDOS LITERÁRIOS: GAYATRI SPIVAK E A MORTE DA LITERATURA COMPARADA COMO AUFHEBUNG
}

\author{
Nabil Araújo
}

\section{POR UMA ANATOMIA DA “MORTE” NOS ESTUDOS LITERÁRIOS}

Há exatos dez anos, vinha à luz, nos EUA, pela prestigiosa editora da Columbia University, Death of a discipline (Morte de uma disciplina), pequeno livro de um nome maior dos estudos literários contemporâneos: Gayatri Chakravorty Spivak. A "disciplina” referida no título não é outra senão a Literatura Comparada, e a "morte" em questão é não meramente constatada pelo livro, mas propriamente performada por ele, como se a um só tempo prevista e prescrita por ele: "Espero que o livro seja lido como o último suspiro de uma disciplina agonizante" (the last gasp of a dying discipline), sentencia, com efeito, Spivak (2003, p. xii), nos agradecimentos que antecedem o primeiro capítulo de Death of a discipline.

De lá para cá, houve diversas tomadas de posição a favor ou contra o referido atestado de óbito disciplinar, dentro e fora dos EUA, aqui no Brasil inclusive (cf. SCHMIDT, 2005), sem que os partidários ou os opositores do livro lograssem esclarecer o caráter, a natureza, afinal, dessa morte declarada em seu título, problema este claramente negligenciável para aqueles simplesmente inclinados a oferecer uma resposta imediata, positiva ou negativa, a uma proposta como a de Spivak, em detrimento de uma análise mais detida dos próprios termos - no caso, o termo 
central - dessa proposta. De que morte se trata, na verdade, quando se diz que uma disciplina morre, ou melhor, quando se chega a matar uma disciplina, a Literatura Comparada, do modo como o faz Spivak em seu livro? O que significa essa morte do ponto de vista da própria dinâmica disciplinar/institucional da Literatura Comparada?

Ocupando-me, neste texto, dessas questões, espero contribuir para uma anatomia da "morte" nos estudos literários.

\section{SPIVAK E A QUERELA COMPARATISTA NOS EUA}

Spivak oferece um índice do caráter "agonizante" da Literatura Comparada logo na abertura do primeiro capítulo de seu livro, quando se refere a uma disciplina em busca de renovação desde o começo da década de 1990, "presumivelmente em resposta à maré ascendente do multiculturalismo e dos estudos culturais", e cita um trecho do prefácio de Charles Bernheimer ao já então célebre Comparative Literature in the Age of Multiculturalism (Literatura Comparada na era do multiculturalismo) (1995), livro cujas primeiras páginas, afirma Spivak (2003, p. 2), contam uma história que poderia ser apreendida como "uma versão da Querela dos Antigos e dos Modernos".

No trecho citado por Spivak, Bernheimer conta ter sido solicitado, no verão de 1992, pelo então presidente da ACLA (American Comparative Literature Association), para nomear e presidir um comitê responsável por escrever um "Report on standards" (Relatório sobre padrões) a ser submetido à associação, documento que, de acordo com os estatutos da ACLA, deve ser preparado a cada dez anos; Bernheimer refere-se, então, aos dois relatórios que antecederam o seu, o primeiro, submetido em 1965, presidido por Harry Levin, o segundo, em 1975, presidido por Tom Greene - o relatório redigido nos anos 1980 tendo sido vetado pelo então presidente do comitê e nunca submetido à associação -, e afirma que ambos "são articulações impressionantemente fortes de uma visão de literatura comparada que, no meu ponto de vista, não mais se aplica às práticas reais na área" (BERNHEIMER, 1995b, p. ix). Os pontos de discordância em relação à referida visão da Literatura Comparada são clara e contundentemente explicitados no próprio "Bernheimer Report" (Relatório Bernheimer) - doravante BR - submetido à ACLA em 1993, e reproduzido na íntegra no livro citado por Spivak, na sequência dos outros dois relatórios, o "Levin Report" (1965) e o “Greene Report” (1975).

Tendo articulado "a concepção da disciplina que prevaleceu através da maior parte dos anos 1950, 1960 e 1970”, os relatórios Levin e Greene 
"atribuem o rápido crescimento da literatura comparada neste país depois da Segunda Guerra a uma nova perspectiva internacionalista", relata o BR (BERNHEIMER ET AL., p. 39); e, alegando que tal "impulso para expandir o horizonte dos estudos literários" derivava-se "de um desejo de demonstrar a unidade essencial da cultura europeia em face de sua recente disrupção violenta", afirma que essa "perspectiva ampliada" da Literatura Comparada "frequentemente não foi além da Europa e da linhagem da alta cultura europeia recuando às civilizações da antiguidade clássica” (ibid., p. 3940). Desse modo, os estudos literários comparativos "tendiam a reforçar uma identificação de Estados-Nação como comunidades imaginadas com línguas nacionais como suas bases naturais", sendo que esse foco em identidades nacionais e linguísticas "é evidente no modo como os relatórios Levin e Greene lidam com a noção de padrões [standards]” (ibid., p. 40) padronização que se fazia necessária a fim de se defender a especificidade da disciplina contra certas ameaças (identificadas como tais sobretudo pelo "Greene Report"): (a) o uso indiscriminado de traduções como ameaça à própria base da Literatura Comparada: leitura e ensino de obras em língua estrangeira no original; (b) o crescimento de programas interdisciplinares como ameaça ao rigor disciplinar da Literatura Comparada; (c) o estudo sincrônico da teoria (literária) como ameaça ao estudo diacrônico da literatura (Ibid., p. 40-41).

Mais do que meramente ameaçado, contudo - sugere o BR -, esse clássico modelo eurocêntrico da Literatura Comparada econtrar-se-ia, então, no começo dos anos 1990, definitivamente em xeque:

O aparente internacionalismo dos anos pós-guerra sustentou um eurocentrismo restritivo que tem sido recentemente contestado a partir de múltiplas perspectivas. A noção de que a promulgação de padrões poderia servir para definir uma disciplina faliu em face de uma porosidade, cada vez mais evidente, das práticas de uma disciplina para outra. Valiosos estudos usando os modelos tradicionais de comparaçãoainda estão sendo produzidos, claro, mas esses modelos pertencem a uma disciplina que já por volta de 1975 sentia-se defensiva e sitiada. O espaço de comparação hoje envolve comparações entre produções artísticas usualmente estudadas por diferentes disciplinas; entre diversas construções culturais daquelas disciplinas; entre tradições culturais ocidentais, tanto elevadas quanto populares, e aquelas de culturas não-ocidentais; entre as produções culturais de povos colonizados pré e pós-contato; entre construções de gênero [gender] definidas como femininas e aquelas definidas como masculinas, ou entre orientações sexuais definidas como convencionais [straight] e aquelas definidas como gay; entre modos raciais e étnicos de significação; entre articulações hermenêuticas de sentido e análises materialistas de seus modos de produção e circulação; e muito mais. Esses modos de contextualização da literatura nos campos expandidos de discurso, cultura, ideologia, raça e gênero [gender] são tão diferentes dos velhos modelos de estudo literário conforme autores, nações, períodos e gêneros [genres], que o termo "literatura" não pode mais descrever adequadamente nosso objeto de estudo (ibid., p. 41-42). 
Não só o termo "literatura" haveria de ser, então, deposto, no que se refere à definição do objeto de estudo do comparatismo, mas, pelos mesmos motivos, o próprio nome da disciplina haveria de ser questionado: como observa o BR, "muitos dos acadêmicos envolvidos em repensar o campo da comparação têm uma relação cada vez mais intranquila com as práticas chamadas 'literatura comparada", chegando-se mesmo a aventar, a partir daí, "a possibilidade de adicionar uma expressão como 'e Estudos Culturais', 'e Crítica Cultural' ou 'e Teoria Cultural' ao título do departamento ou programa a fim de sugerir formas nas quais a velha designação possa estar inadequada" (ibid., p. 42).

Segundo o BR, essas mudanças de nome não foram largamente adotadas "por causa de uma crença geral de que esses novos modos de leitura e contextualização deveriam ser incorporados à própria estrutura da disciplina" (ibid., p. 42), algo alegadamente endossado pelos autores do BR, que se dedica, na sequência, a especificar "como essa incorporação permitirá à literatura comparada posicionar-se como um locus produtivo para trabalho avançado nas humanidades" (ibid., p. 42). Logo de partida, contudo, declara-se que o fenômeno literário "não é mais o foco exclusivo de nossa disciplina" e que os "textos literários estão agora sendo abordados como uma prática discursiva entre muitas outras num complexo, mutável e frequentemente contraditório campo de produção cultural" (ibid., p. 42).

Ora, é preciso admitir que isso pareceria apontar, antes, não para a incorporação de estudos da cultura em geral pela Literatura Comparada, mas para o contrário: a incorporação e, mesmo, a subsunção da literatura, do discurso literário, do próprio comparatismo literário aos "Cultural Studies". E, apesar de os autores do BR declararem, a certa altura, que "nós devemos ser cautelosos em identificarmo-nos com esse campo" (ibid., p. 45), é justamente como uma declaração de identificação da Literatura Comparada aos Estudos Culturais que o BR tenderá a ser tomado - e atacado. Comentando, a propósito, as respostas de autores como Jonathan Culler, Michael Riffaterre e Peter Brooks ao BR, então publicadas, juntamente com outros textos, em Comparative Literature in the Age of Multiculturalism, Bernheimer afirma que eles concebem os Estudos Culturais como "uma ideologização de valores estéticos para o propósito de crítica política" e que veem o BR como "um abandono das verdadeiras formas de estudo literário” (BERNHEIMER, 1995a, p. 1011). "O fato de que o relatório da ACLA foi lido por muitos como um ataque à literatura", retruca Bernheimer (ibid., p. 15) mais à frente, "é talvez um sinal de quão vulneráveis os acadêmicos literários sentem-se na atmosfera acadêmica de hoje”. 
"Uma séria cisão surgiu na ACLA no início dos anos 1990" - relatará, mais tarde, Gerald Gillespie, então presidente da AILC (Associação Internacional de Literatura Comparada), ao fazer o balanço/projeção do comparatismo americano naquela década (GILLESPIE, 1997, p. 16). "Muitos partidários da mais nova constelação" - isto é, aquela surgida "no final dos anos 1980 nas fileiras de comparatistas americanos" e caracterizada por "uma atitude não-literária ou antiliterária" (ibid., p. 16) - "reuniram-se em torno do Bernheimer Report", explica Gillespie, lembrando que um "comitê de membros da ACLA tendendo para os estudos culturais pós-estruturalistas emitiu seus pontos de vista sobre padrões em 1993, enquanto um equivalente espectro contestador de membros da ACLA rejeitou os pressupostos dominantes e muitas recomendações específicas desse documento não-oficial” (ibid., p. 16-17). Nenhum relatório anterior ao BR provocara "tão intensas sensações de interesses cruzados, exasperação e desordem”, observa Gillespie (i bid., p. 17), e conclui que o BR "é amplamente considerado como exibindo a confusão vigente e a falta de missão coerente da Literatura Comparada contemporânea na América", e que a "ausência de qualquer consenso resolvendo o debate sugere uma possibilidade real de que o 'campo' se divida em vários aglomerados ou, talvez, soçobre” (ibid., p. 17). O título necrológico do livro de Spivak publicado alguns anos depois do sombrio vaticínio de Gillespie parece mesmo apontar para a segunda alternativa por ele aventada.

A morte da Literatura Comparada não é declarada, em Spivak, em alinhamento com a frente culturalista da grande querela comparatista; muito pelo contrário: Death of a discipline pode ser lido, na verdade, como um grande libelo contra os "Cultural Studies" e seus efeitos acadêmicos, pedagógicos e ideológicos. Spivak denuncia algo como uma cegueira culturalista em relação à geopolítica global contemporânea, cegueira essa que se deixaria entrever no cerne mesmo do próprio BR. Referindo-se, por exemplo, ao tipo de "coletividades paraestatais multiculturais" criadas pelo retorno, "no mundo pós-colonial e globalizante", de "fronteiras antes demográficas do que territoriais que precedem e são maiores do que o capitalismo", Spivak observa que o "problema com o Bernheimer Report era que ele respondia apenas ao culturalismo inverificado de tais coletividades sintomáticas, os produtores e consumidores estereotipados de Cultural/Ethnic Studies" (SPIVAK, 2003, p. 15).

Isso não quer dizer, evidentemente, que Spivak endosse o tipo de comparatismo eurocêntrico criticado pelo BR; ela remete, a propósito, à migração massiça de intelectuais europeus nas origens da Literatura Comparada americana, "fundada numa hospitalidade intereuropeia" 
(ibid., p. 8), e lembra que, a despeito "de todo o barulho sobre 'estes tempos, [...] o modelo geral em Literatura Comparada parecia, ainda, em 2000, quando essas conferências foram proferidas, ser a Europa e o Oriente extracurricular" (ibid., p. 6). Essa disciplina que se revela renitentemente eurocêntrica, a "pesada Literatura Comparada germânico-românica, vasculhando por controle, racionalizando ignorância sancionada, apontando para enclaves intelectuais europeus já presentes em formações coloniais anteriores como 'história" (ibid., p. 31), justamente ela, bem entendido, é que deveria morrer. Trata-se de uma morte, contudo - e aí residiria seu caráter heterodoxo -, declarada em nome de uma renovação da própria disciplina.

A renovação que tem em vista Spivak não poderia advir, claro está, de uma associação da Literatura Comparada com os Estudos Culturais: "Uma simples fusão entre Literatura Comparada e Estudos Culturais/ Multiculturalismo não vai funcionar ou vai funcionar simplesmente bem demais", sentencia Spivak, e acrescenta: "O que estou propondo é não uma politização da disciplina. Nós estamos na política. Estou propondo um esforço para despolitizar a fim de se afastar de uma política de hostilidade, medo e meias soluções" (ibid., p. 4). Para tanto, Spivak preconiza uma aproximação da Literatura Comparada antes com os chamados "Estudos de Área” (Area Studies), fundados na esteira da Guerra Fria para fins de segurança, voltados para a investigação de "áreas" (geográficas, culturais) estrangeiras (“Oriente Médio”, “América Latina”, etc.), em seus aspectos históricos, sociológicos, políticos, culturais, linguísticos, literários. Os termos da comparação estabelecida por Spivak entre os dois campos disciplinares em questão - "Cultural Studies" e "Area Studies" - são esclarecedores da sua preferência:

(i) Os "Estudos Culturais" acadêmicos, como um fenômeno metropolitano originando-se nas margens de departamentos de língua nacional, opõem-se aos mesmos com não mais do que conviç̧ões políticas presentistas e personalistas baseadas em linguagem metropolitana, frequentemente com conclusões visivelmente previsíveis que não podem se igualar à implícita astúcia política dos Estudos de Área em sua melhor forma; e angariam em si uma reputação de "falta de rigor" bem como de politizar a academia. As línguas das culturas de origem são invocadas, na melhor das hipóteses, como línguas-mãe deslexicalizadas e divertidas (ibid., p. 8).

(ii) Os Estudos de Área exibem qualidade e rigor (características difíceis de se alcançar), combinadas com uma política francamente conservadora ou uma "não" política. Estão ligados à política de poder, e suas conexões com a elite do poder nos países estudados são ainda fortes; a qualidade do aprendizado de línguas é excelente, embora [o mesmo seja] tão geralmente confinado às necessidades do trabalho de campo em ciências sociais; e o processamento de dados é sofisticado, amplo e intenso (ibid., p. 7-8). 
O que Spivak propõe, então, basicamente, é uma espécie de suplementação recíproca entre Estudos de Área e Literatura Comparada, em que esta se beneficiaria dos aspectos positivos inerentes àqueles, renovando-se, e fazendo incidir sobre a fria excelência técnica dos Estudos de Área a dimensão humanista agregada à capacidade de leitura cuidadosa no original que caracterizaria a Literatura Comparada. Declarando sua antiga crença de que a Literatura Comparada deve ser "abarcadora do mundo" (world embracing), Spivak afirma que "a política da produção de conhecimento nos Estudos de Área (e também na antropologia e nas outras 'ciências humanas') pode ser tocada por uma nova Literatura Comparada, cuja marca permanece sendo um cuidado com a língua e o idioma" (ibid., p. 4-5). E ainda: "Sem o suporte das humanidades, os Estudos de Área podem apenas ultrapassar fronteiras [transgress frontiers], em nome de cruzar limites [crossing borders]; e, sem Estudos de Área transformados, a Literatura Comparada permanece aprisionada no interior dos limites que ela não pode cruzar" (ibid., p. 7). Em síntese:

Eu trabalharia para fazer a tradicional sofisticação linguística da Literatura Comparada suplementar os Estudos de Área (e a história, a antropologia, a teoria política e a sociologia) pela abordagem da língua do outro não apenas como uma língua "de campo". No terreno da literatura, precisamos nos mover da Anglofonia, Lusofonia, Teutofonia, Francofonia, etc. Precisamos tomar as línguas do Hemisfério Sul como mídias culturais ativas ao invés de objetos de estudo cultural pela ignorância sancionada do migrante metropolitano. Não podemos ditar um modelo para isso a partir dos escritórios da American Comparative Literature Association (ibid., p. 9).

Mais à frente, Spivak postula: "A Literatura Comparada e os Estudos de Área podem trabalhar juntos na promoção não apenas das literaturas nacionais do Sul global mas também da escrita de inúmeras línguas nativas no mundo que foram programadas para desaparecer quando os mapas foram feitos" (ibid., p. 15). Encontra-se aí em jogo a preocupação central da autora com "a especificidade literária do autóctone" (the literary specificity of the autochthone), a qual, segundo ela, "perdida no embaralhamento dos Estudos Culturais com a Literatura Comparada, não podia absolutamente aparecer em Comparative Literature in the Age of Multiculturalism" (ibid., p. 15).

Diante do impasse gerado pela violenta querela que se diz ter dividido, a partir do início dos anos 1990, o campo comparatista americano entre acadêmicos "literários" e acadêmicos "culturalistas", Spivak desfere, em suma, com Death of a discipline, um duríssimo golpe contra o multiculturalism declinado em "Global English" pelos "Cultural Studies", 
ao mesmo tempo em que declara nada menos do que a morte da Literatura Comparada, mas em nome de uma renovação da Literatura Comparada. É do caráter histórico-estrutural dessa morte como fundação/legitimação, como ato (re)fundador da Literatura Comparada, e de suas consequências, que seria preciso agora falar.

\section{APOCALIPSE SPIVAKIANO: A MORTE DA LITERATURA COMPARADA COMO AUFHEBUNG}

Quem, ao se indagar pelo estatuto, pelo propósito, pelas consequências da morte da Literatura Comparada em Spivak, tomasse por base o que disseram a respeito os mais destacados resenhistas e comentadores norte-americanos de Death of a discipline, provavelmente concluiria que a declaração de morte no livro é para ser tomada, na verdade, de modo não literal.

"Death of a discipline de Gayatri Chakravorty Spivak não nos conta que a Literatura Comparada está no fim. Ao contrário, traça um exigente e urgente futuro para a área" - afirma, por exemplo, Judith Butler, em comentário reproduzido na quarta capa do livro de Spivak, ao qual se segue o de Jean Franco, segundo quem "Death of a discipline é não um lamento mas uma promessa". John Mowitt - segundo quem Death of a discipline "é certamente a mais importante, bem sustentada declaração sobre a disciplina da Literatura Comparada surgida em inglês desde [...] Comparative Literature in the Age of Multiculturalism" (MOWITT, 2004/2005, p. 122) - observa, por sua vez: "Porque a morte é mais ou menos do que a morte, o texto de Spivak não é nem mórbido nem sombrio" (ibid., p. 122). Comentários desse tipo atuam no sentido de amenizar, até de subestimar o aspecto propriamente necrológico do programa comparatista spivakiano, como se nos instassem a restringir nossa atenção à renovação desenhada por Spivak em detrimento da inegável declaração de morte a partir da qual tal renovação, não obstante, se enuncia.

Christopher Bush é quem logra avançar alguma problematização do que tende a ser negligenciado pelos demais comentadores. "Podese esperar que um texto intitulado Death of a discipline seja elegíaco ou, ao menos, ansioso, e, no entanto, ele fala em grande parte do que a Literatura Comparada vai fazer, vai ser, ou, antes, pode fazer ou ser", observa Bush (2005, p. 208); essa "provocação do título", ele explica, "não é nem um lamento nem uma convocação às armas, mas a denominação de uma estrutura" (ibid., p. 207). Mais à frente: "Um título é só um título 
e a morte não é explicitamente tematizada no texto de Spivak. Nesse caso, contudo, a estrutura é mais importante do que o tema. A relação com a morte que descrevi aparece no texto de Spivak como o futuro" (ibid., p. 208). Daí, o problema: "como podemos ler figuras de morte como prefigurações de uma disciplina por vir?” (ibid., p. 208). Mais do que isso - poder-se-ia acrescentar -, tal morte prefiguradora, a que isso se presta? Ela é ditada, afinal, a quem e por quê? Em que termos? Por que tipo de demanda e em vista de que tipo de benefícios? Com que consequências?

Parece que essas questões simplesmente não se colocam para os leitores norte-americanos em geral. Não estranha, pois, ter sido um comentador não americano, o francês Didier Coste (Université Bordeaux 3), quem tenha - duramente - interpelado o livro de Spivak nesse sentido, numa resenha publicada em francês, ainda em 2003, em Recherche Littéraire/Literary Research, o periódico oficial da AILC (Associação Internacional de Literatura Comparada). Nunca se limitando a uma paráfrase do livro por ele então resenhado, Coste intenta, na verdade, do começo ao fim, algo como uma desmistificação do discurso spivakiano em Death of a discipline.

Indo direto à declaração de morte no título do livro, ele afirma que "não é difícil adivinhar que a disciplina da qual se deve declarar a morte para poder refundá-la não é outra senão a Literatura Comparada" (COSTE, 2003, p. 49), mas não encara esse procedimento com serenidade, especulando sobre as necessidades e as motivações bem pouco nobres que subjazeriam ao mesmo: "mergulhado como estamos numa cultura comercial da magia e da moda, não podemos deixar de nos interrogar, além de um votum mortis que tem todas as características de uma profecia auto-realizada, sobre as condições de pensamento que fazem muitos de nossos colegas americanos buscarem uma tal estratégia" (ibid., p. 49). Seria preciso atentar, pois, na análise do "spivakismo conquistador" [le "spivakisme" conquérant], para "os sintomas de uma mercantilização absoluta do pensamento do literário revelados pelo lançamento do votum mortis e pelos conteúdos de seu suporte, o pequeno livro negro (le petit livre noir)" (ibid., p. 50). Coste propõe-se, nesse sentido, "uma breve análise ideológica e epistemológica, tão cerrada quanto possível, do discurso spivakiano e da enciclopédia que o sustenta" (ibid., p. 50). Bem entendido, Coste buscará denunciar no discurso necrológico spivakiano nada menos do que uma usurpação mercadológica do "pensamento do literário" (na forma da Literatura Comparada), sob a égide de uma "cultura comercial da magia e da moda", provavelmente visando-se a algum benefício (lucro?) privado. 
Observe-se que os termos da denúncia e da análise ideológicoepistemológica então empreendidas por Coste contra Spivak são bem próximos daqueles empregados por Kant, mais de dois séculos antes, contra certos "usurpadores" da filosofia, num opúsculo relativamente pouco comentado mas tornado célebre em nosso tempo pela leitura que dele fez Jacques Derrida a propósito do "tom apocalíptico". O opúsculo em questão intitula-se Von einem neuerdings erhobenen vornehmen Ton in der Philosophie (1796), "Sobre um recentemente enaltecido tom de distinção na Filosofia”, segundo a tradução de Valério Rohden, " "D’un ton grand seigneur adopté naguère en philosophie” (De um tom grãosenhor adotado há pouco em filosofia), segundo a tradução francesa de L. Guillermit, aquela citada por Derrida - de onde, aliás, o título de seu próprio texto: "D’un ton apocalyptiqueadopté naguèreen philosophie" (De um tom apocalíptico adotado há pouco em filosofia), evidente retomada do título kantiano, assim justificada: "[eu quis] mimar segundo a citação, mas também transformar em gênero, e então parodiar, deportar, deformar o título bem conhecido de um opúsculo talvez menos bem conhecido de Kant" (DERRIDA, 1981, p. 447).

"D'un ton apocalyptique..." é o texto da conferência proferida por Derrida em 1980 no Colóquio de Cerisy "Les fins de l'homme: à partir du travail de Jacques Derrida" (Os fins do homem: a partir do trabalho de Jacques Derrida), dirigido por Philippe Lacoue-Labarthe e Jean-Luc Nancy, e do qual participou a própria Spivak (com uma comunicação sobre a relação entre o trabalho de Derrida e o discurso da economia política). De modo a pautar uma leitura possível de Coste-lendo-Spivak, acompanhemos Derrida nas linhas gerais de sua leitura de Kant-lendoseus-adversários-filosóficos.

No opúsculo contra o alegado "tom grão-senhor" (vornehmen Ton) assumido por certos filósofos contemporâneos seus, Kant - observa Derrida - "analisa menos um tom em filosofia do que denuncia uma maneira de se dar ares; [...] uma maneira ou um maneirismo que precisamente não lhe parece de muito bom tom em filosofia, e que marca já, então, um desvio em relação à norma do discurso filosófico"; ele ataca, na verdade, mais gravemente, "um tom que anuncia qualquer coisa como a morte da filosofia" - morte essa "associada à ideia de uma revelação sobrenatural, de uma visão provocando uma exaltação mística ou, ao menos, uma pose de visionário" (ibid., p. 448). Kant, em suma, submete a julgamento "aqueles que, pelo tom que adotam e pelo ar que se dão no momento de dizer certas coisas,

\footnotetext{
${ }^{1}$ Publicada no número 10 (2010) da revista Studia Kantiana, da Sociedade Kant Brasileira.
} 
põem a filosofia em perigo de morte e dizem à filosofia ou aos filósofos a iminência de seu fim", sendo que a "iminência, aqui, não importa menos do que o fim" (ibid., p. 449). Sim, pois esses "mistagogos da modernidade", segundo Kant, "não nos dizem simplesmente que eles veem, tocam ou sentem. Eles pressentem, eles antecipam, eles aproximam, eles farejam, são os homens da iminência e do sinal" (ibid., p. 458). Digamos, pois, em síntese, que mais do que meramente constatar a aproximação do fim, eles efetivamente a performam em seu discurso, projetando- $a$ em direção ao outro pelo emprego de um tom apocalíptico.

Parece irritar sobremaneira a Coste justamente o modo como o fim da Literatura Comparada se vê projetado em Death of a discipline, livro que se quereria nada menos do que "o último suspiro de uma disciplina agonizante" (Spivak), a previsão da morte da Literatura Comparada afigurando-se, aí, indissociável de uma prescrição dessa morte, o livro todo convertendo-se, assim, num altissonante votum mortis, na manifestação de um desejo de morte encarnado numa profecia necrológica autorealizável, mas cuja alegada necessidade se veria na dependência de uma argumentação no mínimo ardilosa da parte de Spivak: "A Literatura Comparada e todo comparatismo são desde o começo apresentados como contraditórios e especiosos", observa Coste (2003, p. 51); e ainda: "O eurocentrismo da velha guarda da Sorbonne nos anos 1970 é estigmatizado como um vício inerente que justifica a intervenção profética spivakiana, não como uma aberração corrigível do interior de uma visada científica" (ibid., p. 51). Sob uma tal encenação apocalíptica, estaria em curso, já se disse, a "mercantilização absoluta do pensamento do literário", algo como a usurpação desse pensamento, sob a forma da Literatura Comparada, regida por um imperativo mercadológico e visando-se, ao que tudo indica, a algum tipo de benefício.

"Aqueles que falam nesse tom, Kant está certo de que eles esperam algum benefício", prossegue Derrida (1981, p. 449) em sua leitura, explicando, na sequência, ser justamente isso o que interessa a ele próprio, Derrida, antes de tudo, aquilo a respeito do que gostaria, então, de falar: "de um certo tom e disso que acontece à filosofia como sua morte, da relação entre esse tom, essa morte, e o benefício aparentemente calculado dessa mistagogia escatológica" (ibid., p. 450); e ainda: "O escatológico diz o eskhaton, o fim, ou antes o extremo, o limite, o termo, o último, aquilo que vem in extremis fechar uma história, uma genealogia ou muito simplesmente uma série numerável” (ibid., p. 450).

Voltando à análise do opúsculo: "Os mistagogos fazem uma cena, eis o que interessa a Kant" (ibid., p. 450). "Mas em que momento os mista- gogos entram em cena e às vezes em transe? Em que momento 
começam a proceder ao misterioso?”, pergunta Derrida, e responde: “No instante em que a filosofia, mais precisamente o nome da filosofia, perdeu sua primeira significação, seine erste Bedeutung. E essa significação primitiva, Kant não o duvida por um só instante, é o 'saber-viver racional', literalmente uma sabedoria de vida que se regra por um saber ou uma ciência (wissenschaftliche Weisheit)"; assim: "No instante em que o nome da filosofia perde sua significação ou sua referência original, esse nome desde então vazio ou usurpado, esse pseudônimo ou esse criptônimo, que é antes de tudo um homônimo, os mistagogos dele se apoderam" (ibid., p. 450).

Poder-se-ia dizer que também para Coste a Literatura Comparada como instância do "pensamento do literário" encontra-se originária e essencialmente investida de uma racionalidade ou cientificidade fundamental, de uma "visada científica" no interior da qual os problemas levantados por Spivak, longe de justificarem a morte da disciplina, poderiam ser prontamente "corrigidos" sem maiores alardes. Pelo que sugere Coste, é essa perspectiva racional/científica a que vigora no estável comparatismo francês, ao que tudo indica resguardado da "cultura comercial da magia e da moda" hegemônica nos EUA, estado de coisas que, devidamente levado em conta, deveria no mínimo relativizar o diagnóstico e o prognóstico de Spivak para a Literatura Comparada, evitando-se, com isso, a usurpação do nome da disciplina então em curso: "Desde os primeiros parágrafos do livro, aprendemos que as coisas mudam a toda velocidade na Literatura Comparada nos Estados Unidos", observa, com efeito, Coste (2003, p. 56), e acrescenta: "Numa perspectiva menos míope e menos a-histórica, seria também surpreendente constatar que quase nada mudou na concepção da disciplina na França desde dezenas de anos".

Ora, no que se refere especificamente à Literatura Comparada, Spivak (2003, p. 6) observa que a despeito "de todo o barulho sobre 'estes tempos"', parecia vigorar, ainda, nos EUA, quando da realização de suas conferências, o modelo geral herdado da Europa. Poder-se-ia alegar, assim, que justamente porque Coste, tal como Kant em sua época, encontrase demasiadamente bem instalado num status quo disciplinar de longa duração, é que se mostra incapaz de vislumbrar o novo horizonte projetado por Spivak para além da morte declarada da Literatura Comparada, incapaz de ver aquilo mesmo que ela não só vê, mas anuncia, aproxima, antecipa, acelera... - e o faz, contudo, com base em quê? Desfrutando de que tipo de privilégio ou prerrogativa?

Voltando à análise derridiana do opúsculo kantiano: segundo Kant, os mistagogos usurpadores do nome da filosofia são pessoas que "se classificam como fora do comum, mas têm isto em comum: dizem-se em contato direto e intuitivo com o mistério. E querem atrair, seduzir, conduzir para o mistério e pelo mistério" (DERRIDA, 1981, p. 451). E ainda: 


\begin{abstract}
Mystagogein é isso mesmo: conduzir, iniciar no mistério; é a função do mistagogo ou do sacerdote iniciador. Essa função agógica de iniciador de homens, de duce, de Führer, de leader, o coloca acima da massa que ele manipula pelo intermédio de um pequeno número de adeptos reunidos numa seita de linguagem críptica, um bando, uma súcia ou um pequeno partido com suas práticas ritualizadas. Os mistagogos pretendem deter como algo privado o privilégio de um misterioso segredo [...]. [...] Eles não o transmitem jamais a outrem em linguagem corrente, somente por iniciação ou por inspiração. O mistagogo é o philosophus per initiationem ou per inspirationem (ibid., p. 451-452).
\end{abstract}

Os mistagogos teriam em comum, segundo Kant, nunca deixarem de "se tomar por senhores (sich für Vornehme halten), por seres de elite, sujeitos distintos, superiores e à parte da sociedade" (ibid., p. 452). Daí a série de oposições assinalada por Derrida: "eles menosprezam o trabalho, o conceito, a escolaridade, creem ter acesso ao que é dado sem esforço, graciosamente, pela intuição ou pelo gênio"; e ainda: "A oposição hierarquizada do dom ao trabalho, da intuição ao conceito, do modo genial ao modo escolar (geniemässig/schulmässig) é homóloga à oposição entre uma aristocracia e uma democracia, eventualmente entre uma oligarquia demagógica e uma democracia racional" (ibid., p. 452). Distinguem-se, aí, a "voz da razão" e a "voz do oráculo" (ibid., p. 453). Kant não perdoa os filósofos de profissão quando adotam um tom grão-senhor "porque elevando assim o tom eles se içam acima de seus colegas ou confrades (Zunftgenossen), os lesam em seu direito inalienável à liberdade e à igualdade em tudo o que toca à simples razão", e o fazem precisamente "pervertendo a voz da razão, misturando as duas vozes do outro em nós, a voz da razão e a voz do oráculo" (ibid., p. 453). Quanto às motivações subjacentes a essa "perversão" da filosofia, Kant não tem dúvida de que aqueles que a perpetram o fazem "para se dar grandes ares, ocupar por simulacro e mímica o lugar dos grandes, usurpar, assim, um poder de essência simbólica" (ibid., p. 460).

Ora, é claro que, nesse mesmo sentido, a acusação de hermetismo mistificador e antidemocrático frequentemente feita ao "estilo" de Spivak viria totalmente ao encontro da crítica ideológico-epistemológica que Coste dirige a Death of a discipline em nome da "cientificidade" da Literatura Comparada. Coste (2003, p. 54) evoca, assim, em relação a Spivak, "a teatralidade de suas bruscas manobras e a estética da inapreensibilidade que marcam [suas] tomadas de posição em forma de esquivas", bem como seu "respeito profundo por tudo aquilo que cristaliza a confusão dos humanistas por tempos de inumanidade", afirmando ser "difícil resistir à tentação de ataques ad feminam que o spivaspeak torna tão fáceis". Coste professa-se, então, fiel ao "terreno da responsabilidade e da coerência científicas, [...] abandonado desde há muito tempo pela 
autora de Death of a discipline" (Ibid., p. 54). Marca maior desse abandono seriam os procedimentos de leitura empreendidos por Spivak em seu livro, apesar da declarada preocupação com a questão da leitura (e de sua centralidade na Literatura Comparada):

\begin{abstract}
As poucas amostras de análise que nos são oferecidas aproximam textos numa total arbitrariedade, saltam de conteúdos situacionais a microssinais estilísticos, lexicais ou sintáticos, ou vice-versa, sem que jamais seja claramente formulada a questão da posição leitoral, ou aquela dos limites da intertextualidade ou de sua relação com a configuração dos universos de referência no mundo representado e no sistema textual considerado (ibid., p. 57).
\end{abstract}

Coste identifica, em suma, no livro de Spivak, uma "reivindicação subjacente do irracional", um "ódio latente à cientificidade das ciências humanas", mas que não seriam nunca claramente confessados porque "os procedimentos que daí provêm procuram ao mesmo tempo extrair sua autoridade de saberes filosóficos, filológicos, políticos e psicanalíticos sobre a ostentação dos quais se constroem as hierarquias universitárias num mercado oligopólico global" (ibid., p. 57). Encontrar-se-ia, pois, aí em jogo algo como a usurpação de um poder simbólico por meio da ostentação de um saber apenas aparente, da sustentação estilística de uma mera aparência de saber, com vistas a benefícios/privilégios acadêmicomercadológicos.

A desmistificação, em Coste, da obscuridade do "spivaspeak" se dá, para todos os efeitos, pela ação ou por efeito de um esclarecimento de tipo científico. "E é em nome de uma Aufklärung que Kant [...] põe-se a desmistificar o tom grão-senhor”, afirma, a propósito, Derrida (1981, p. 466), observando na sequência:

Nos dias de hoje, nós não podemos deixar de ter herdado dessas Luzes, não podemos e não devemos, é uma lei e um destino, renunciar à Aufklärung, dito de outra forma, a isso que se impõe como desejo enigmático da vigilância, da vigília lúcida, da elucidação, da crítica e da verdade, mas de uma verdade que ao mesmo tempo guarda nela o desejo apocalíptico, dessa vez como desejo de claridade e de revelação, para desmistificar ou, se preferirem, para desconstruir o próprio discurso apocalíptico e, com ele, tudo o que especula sobre a visão, a iminência do fim, a teofania, a parusia, o julgamento final, etc. (ibid., p. 466).

Assim sendo, o "desejo de verdade" que impulsiona a desmistificação iluminista do discurso apocalíptico confundir-se-ia, ele próprio, com certo "desejo apocalíptico" como "desejo de claridade e de revelação". Seria preciso cuidado, pois, "O interesse ou o cálculo podem aí ser dissimulados sob o desejo de luz", explica Derrida (ibid., p. 467), "bem escondidos sob o desejo declarado de revelação. E uma dissimulação pode esconder outra”. 
Não, a desconstrução do discurso apocalíptico não poderia limitarse, muito menos confundir-se com uma crítica de tipo iluminista a esse mesmo discurso. É por isso que, ainda no início de sua leitura, referindose à acusação de Kant aos "mistagogos", Derrida afirma que "vou, talvez, repetindo o que ele faz, chegar a fazer o contrário - ou de preferência outra coisa" (ibid., p. 450) - o mesmo podendo ser dito acerca desta reconstituição do andamento da acusação de Coste a Spivak, na qual se procura evitar a sobreposição dos passos, indo-se na direção, portanto, de uma outra coisa... Voltemo-nos, a propósito, uma vez mais, ao próprio Derrida:

\begin{abstract}
Quem assume o tom apocalíptico vem lhes comunicar, se não lhes dizer, alguma coisa. O quê? mas a verdade, é claro, e comunicar-lhes que ele a revela a vocês, o tom é revelador de algum desvelamento em curso. Desvelamento ou verdade, apofântico da iminência do fim, do que quer que seja que chega, no limite, ao fim do mundo. Não somente a verdade como verdade revelada de um segredo sobre o fim ou do segredo do fim. A verdade ela própria é o fim, a destinação, e que a verdade desvele a si é o advento do fim. A verdade é o fim e a instância do juízo final. A estrutura da verdade seria, aqui, apocalíptica (ibid., p. 468; grifo meu).
\end{abstract}

Um comentarista como Christopher Bush chega a perceber que, em Death of a discipline, mais importante do que a morte como tema - dirse-ia: como "verdade revelada de um segredo sobre o fim ou do segredo do fim" - é a morte como estrutura - dir-se-ia: como "estrutura apocalíptica da verdade"; assim: "Não é um texto sobre alguma coisa que chegou ou está chegando a um fim; é um texto sobre alguma coisa por vir, ou, antes, o porvir [the to-come]. A morte da Literatura Comparada é seu futuro" (BUSH, 2005, p. 208). Em outras palavras, a verdade da Literatura Comparada é sua morte, posto que só sua morte traz em si - anuncia, implica ou instaura seu futuro, seu por-vir como disciplina. Eis o que se poderia chamar, em suma, de estrutura apocalíptica da fundação em Spivak.

Voltando a Derrida (1981, p. 468): "Então, a quem assume o tom apocalíptico, perguntar-se-á: em vista de que e com que fins? Para conduzir aonde, neste instante ou dentro em breve?". Referindo-se à reação de Christopher Bush à "ideia da morte" em Death of a discipline, Eric Hayot (2005, p. 259) pergunta a Spivak se se trataria, para ela, de uma "estruturação tanatológica de algum tipo". Spivak esclarece, então, que se trata, antes, do "gênero da elegia" (the genre of elegy), isto é, ela diz, "não o elegíaco, mas a característica da elegia, você reconheceria que isso é uma elegia, que ao fim o rei está morto, vida longa ao rei” (SPIVAK apud HAYOT 2005, p. 259). É isto, pois, o que aí parece interessar sobremaneira a Spivak: algo como a permanência disso que morreu mas está vivo, ou, 
antes, está vivo justamente porque morreu, porque de alguma forma conservou-se na morte. "Você diz, no fim da elegia, que o objeto da elegia está vivo", explica a autora, afirmando, então, tratar-se de "um tipo de anúncio de Aufhebung" (ibid., p. 259).

Ora, essa referência ao célebre conceito hegeliano esclarece muito acerca dos fins da adoção do tom apocalíptico no gesto de fundação/ legitimação disciplinar da Literatura Comparada em Spivak. Aufhebung: digamos, em português, suprassunção, acompanhando, nisso, o tradutor brasileiro da Phänomenologie des Geistes (Fenomenologia do Espírito) (1807) eda Enzyklopädie der philosophischen Wissenschaften (Enciclopédia das ciências filosóficas) (1830), segundo quem, para traduzir o verbo alemão aufheben, central na filosofia de Hegel, suprassumir é melhor do que sobressumir, "não só porque 'sobre' tem a ressonância de 'em cima', e 'supra' a de 'acima', mas porque a ambiguidade sumir/suprassumir fica muito bem para este 'desaparecer conservante' que é o aufheben" (MENESES, 1995, p. 10). Voltemo-nos ao que diz o próprio Hegel a esse respeito em sua Enzyklopädie, segundo a tradução de Meneses:

Importa recordar aqui a dupla significação de nosso termo alemão aufheben. Por aufheben entendemos primeiro a mesma coisa que "hinwegräumen" [abrogar], "negieren" [negar], e por conseguinte dizemos, por exemplo, que uma lei, um dispositivo são "aufgehoben" [ab-rogados]. Mas além disso significa também o mesmo que aufbewahren [conservar]. Essa ambiguidade no uso da língua, segundo a qual a mesma palavra tem uma significação negativa e uma significação positiva, não se pode considerar como contingente, nem se pode fazer à linguagem a censura de dar azo à confusão; mas tem-se de reconhecer aí o espírito especulativo de nossa língua, que vai além do simples ou-ou do entendimento (HEGEL, 1995, p. 194-195).

Aufheben implicando, pois, a negação/ab-rogação de uma coisa sua anulação, sua abolição, sua eliminação - ao mesmo tempo que sua preservação, sua conservação, dir-se-ia tratar-se, em suma, de um "superar conservando”. Ora, essa ideia do suprassumir como uma superação-pelaconservação (ou uma conservação-pela-superação) é essencial para o programa comparatista spivakiano, ancorado que está numa declaração da morte-como-futuro da Literatura Comparada, e é o que o diferenciaria, aliás, em termos de legitimidade, da malograda tentativa anterior de reformar o comparatismo literário em conformação a uma agenda culturalista. Isso porque a reforma comparatista promovida pelos "Cultural Studies", justamente porque sobrevinda de fora, acabaria por implicar, como o deixa claro o Bernheimer Report, algo como a mera subsunção (e não a suprassunção) do literário e da Literatura Comparada ao campo, a um só tempo mais vasto e menos específico, dos "estudos da cultura", ao 
passo que o "anúncio de Aufhebung" feito em Death of a discipline lograria reformar de dentro, por assim dizer, o campo comparatista, conservando-o como campo disciplinar autônomo, a superação da Literatura Comparada por ele promovida implicando a preservação da própria Literatura Comparada como disciplina e de sua legitimidade institucional.

A morte como suprassunção disciplinar é o que permitiria, enfim, a Spivak reconfigurar, à sua maneira, o campo comparatista, determinando o que aí vale e o que não vale mais em termos teórico-metodológicos, não obstante mantendo-se no interior do mesmo e gozando da estabilidade edos benefícios institucionais garantidos sob o nome da Literatura Comparada. É o nome, pois, da disciplina, que seria preciso acima de tudo resguardar e conservar, quaisquer que sejam as mudanças propostas, tudo se passando como se se tratasse de readequar o nome à coisa, o mesmo nome, e tudo o que ele implica em termos institucionais, a uma nova coisa. Justamente essa, aliás, a função performativa da distribuição do "novo" (new) e do "velho" (old) associados ao mesmo nome de disciplina - Comparative Literature na economia discursiva de Death of a discipline.

O título original das conferências de Spivak em 2000 era "The new comparative literature" (A nova literatura comparada). Três anos depois, nos agradecimentos de Death of a discipline, Spivak (2003, p. xii) afirma não ter mudado "nada da urgência de meu apelo por "uma nova literatura comparada"; mas é a morte da disciplina que ocupa agora o primeiro plano, não havendo, pois, renovação sem morte - a projeção, por Spivak, da nova Literatura Comparada por ela sonhada sendo indissociável da projeção, também por Spivak, de uma doravante velha (morta?) Literatura Comparada. É assim que, concomitantemente a uma "new Comparative Literature", Death of a discipline nos fala de uma "old Comparative Literature": (a) "o melhor da velha Literatura Comparada: a habilidade de ler cerradamente no original" (ibid., p. 6); (b) "A velha Literatura Comparada não pedia ao estudante para aprender todas as línguas hegemônicas" (Ibid., p. 10); (c) "se trabalharmos tão duro quanto a antiga Literatura Comparada [old-fashioned Comp. Lit.] é conhecida por ser capaz de fazer" (ibid., p. 13); (d) "A confrontação entre a velha Literatura Comparada e os Cultural/Ethnic Studies pode ser polarizada em humanismo versus política identitária" (ibid., p. 28).

Nesse jogo do "velho" e do "novo" performa-se, pois, a própria suprassunção da Literatura Comparada pela Literatura Comparada visada por Spivak: nega-se/abroga-se a Literatura Comparada em vista do que doravante será tomado por "velho", conservando-se a Literatura Comparada - sobretudo o nome da disciplina, mas também determinados traços da dita "velha" Literatura Comparada -, em vista do que aí, então, (auto)institui-se e (auto)legitima-se como "novo". 
100 - Remate de Males 35.1

\section{REFERÊNCIAS BIBLIOGRÁFICAS}

BERNHEIMER, Charles. The anxieties of comparison. In: (Ed.). Comparative literature in the age of multiculturalism. Baltimore/London: Johns Hopkins University Press, 1995a. p. 1-17.

BERNHEIMER, Charles. Preface. In: (Ed.). Comparative literature in the age of multiculturalism. Baltimore/London: Johns Hopkins University Press, 1995b. p. ix-xi.

BERNHEIMER, Charles et al. The Bernheimer Report, 1993: Comparative Literature at the turn of the century. In: (Ed.). Comparative literature in the age of multiculturalism. Baltimore/London: Johns Hopkins University Press, 1995. p. 39-48.

BUSH, Christopher. Deaths of a discipline. Comparative Literature, v. 57, n. 3, p. 207-213, 2005.

COSTE, Didier. Votum mortis. Recherche Littéraire/Literary Research, v. 20, n. 39-40, p. 49-57, 2003.

DERRIDA, Jacques. D’un ton apocalyptique adopté naguère en philosophie. In: LACOUELABARTHE, Philippe; NANCY, Jean-Luc (Dir.). Les fins de l'homme: à partir du travail de Jacques Derrida. Paris: Galilée, 1981. p. 445-479. [Ed. port.: DERRIDA, Jacques. De um tom apocalíptico adotado há pouco em filosofia. Trad. de Carlos Leone. Lisboa: Vega, 1997.]

GILLESPIE, Gerald. Comparative Literature of the 1990s in the U.S.A. In: CARVALHAL, Tania Franco (Ed.). Comparative literature worldwide: issues and methods / La littérature comparée dans le monde: questions et méthodes. Porto Alegre: L\&PM/ VITAE/AILC, 1997. p. 15-37.

HAYOT, Eric. "The slightness of my endeavor": an interview with Gayatri Chakravorty Spivak. Comparative Literature, v. 57, n. 3, p. 256-272, 2005.

HEGEL, G. W. F. Enzyklopädie der philosophischen Wissenschaften im Grundrisse [1830]. Ed. utilizada: HEGEL, G. W. F. Enciclopédia das ciências filosóficas em compêndio. v. 1 (A ciência da lógica). Trad. de Paulo Meneses. São Paulo: Loyola, 1995.

MENESES, Paulo. Nota do tradutor. In: HEGEL, G. W. F. Enciclopédia das ciências filosóficas em compêndio. v. 1 (A ciência da lógica). Trad. de Paulo Meneses. São Paulo: Loyola, 1995. p. 9-11.

MOWITT, John. The work of Comparative Literature in the Era of Globalization. Clio, v. 34, n. 1-2, p. 121-129, Fall 2004/Winter 2005.

SCHMIDT, Rita Terezinha. Alteridade planetária: a reinvenção da Literatura Comparada. Revista Brasileira de Literatura Comparada, n. 7, p. 113-129, 2005.

SPIVAK, Gayatri Chakravorty. Death of a discipline. New York: Columbia University Press, 2003. 